\title{
Correlation of CoViD-19 Infection and Tumorigenesis
}

\author{
Alireza Ebrahimi 1,*(D) \\ 1 Department of Hematology, Faculty of Medical Sciences, Tarbiat Modares University, Tehran, Iran \\ * Correspondence: a.ebr@modares.ac.ir;
}

Scopus Author ID 57195154325

Received: 20.12.2020; Revised: 12.01.2021; Accepted: 15.01.2021; Published: 20.01.2021

\begin{abstract}
The outbreak of the novel coronavirus disease 2019 (CoViD-19) has emerged to be the biggest global health issue globally and has now infected over 20 million people. The correlation between inflammation during viral infection and cancer is unknown. This review surveys soluble proteins produced during the severe viral infection and might influence tumorigenesis. Inflammation is a fast and primitive defense reaction to pathogens that limits tissue damage and stimulates repair mechanisms. It is initiated by local cells that detect pathogens or trauma and send chemical messengers such as IL-1, IL-6, and TNF- $\alpha$ to other cells. Sometimes, the overexpression of chemical messengers can influence the whole body and change signaling pathways in vulnerable cells. This comprehensive review collected information about CoViD-19, cytokine release syndrome (CRS), coagulation system changes, cancer initiation, and cancer progression. There are concerns about future challenges in convalescent patients who had severe infection and cytokine storm.
\end{abstract}

Keywords: coronavirus disease; cytokine release syndrome; CoViD-19; IL-6; cancer; CRS.

(C) 2020 by the authors. This article is an open-access article distributed under the terms and conditions of the Creative Commons Attribution (CC BY) license (https://creativecommons.org/licenses/by/4.0/).

\section{Introduction}

Coronaviruses have emerged as deadly agents in the past two decades, which Tyrell and Bynoe identified in 1966 [1]. The new contagious coronavirus disease 2019 (CoViD-19) has infected more than 20,158,128 people and has been responsible for more than 736,190 deaths from August 10, 2020 (World Health Organization). Pathogenic severe acute respiratory syndrome-coronavirus 2 (SARS-CoV-2), the cause of CoViD-19, is a beta coronavirus $[2,3]$. This virus has a positive single-stranded RNA with an envelope containing transmembrane spikes that anchor to infected cells [4]. Bats and birds are typical hosts for the CoViD-19 virus [5]. SARS-CoV-2 is also similar to other pathological zoonotic coronaviruses such as SARSCoV-1 in 2002 and the Middle East respiratory syndrome (MERS) in 2012, which can cause severe respiratory illnesses in the world [6]. SARS-CoV-2 is more contagious than SARSCoV-1 [7] because of its high virulence factor and the absence of pre-existing immunity [8].

The virus binds with spike protein to the host receptors via the receptor-binding domains (RBDs) of angiotensin-converting enzyme 2 (ACE2) [9]. The ACE2 protein is in multiple organs, including the respiratory system, gastrointestinal tract, lymph nodes, thymus, bone marrow, spleen, liver, kidney, and brain [9], but is absent in T cells [10].

CoViD-19 disease is often associated with fever (87-98\%), cough (55-80\%) and lethargy (38-70\%) [11], dyspnea (30-50\%), sputum production (30\%), chest pain $(20 \%)$, myalgia (30-45\%), diarrhea (3-14\%) and headache (15\%), and also with anosmia and hyposmia [12]. 
Older adults (especially those older than 65 years [13]), cancer patients, patients with weak immune systems, diabetes, hypertension, and heart disease might be more affected by constant medical appointments, infusion clinic visits, and clinical exams [14]. Their disease and treatment immunosuppress patients with different cancers, so they are at risk of CoViD19. Furthermore, patients with hematology malignancies will be at higher risk because of advanced age and comorbidities such as transplantation or transfusion [11,12].

Most of the patients had normal CBC results (normal RBC, WBC, and platelet count) and lactate dehydrogenase (LDH), but some patients with critical situations have significantly lower CD45+, CD3+, CD4+, CD8+, CD19+ and CD16/56+ counts along with lymphopenia, elevated LDH and D-dimer and neutrophilia. In peripheral blood, film was seen lymphopenia with a few reactive lymphocytes [11,15]. Also, immunohistochemical staining and flow cytometry analysis showed that CD4 positive and CD8 positive T cells population decreased in the lymph nodes and spleen [16].

Lymphopenia is reported in $63 \%$ to $83 \%$ of patients with CoViD-19. Patients with decreased CD8+ $\mathrm{T}$ cells and $\mathrm{B}$ cells have severe symptoms and inadequate response to treatments [6]. Other laboratory findings were leukopenia (9\% to 25\%), leukocytosis (24\% to $30 \%)$, and elevated transaminases (37\%) [6].

In CoViD-19 infection, we can usually see fever, organ dysfunction, hypoalbuminemia, capillary leak, and microvascular thrombosis. Moreover, the quantity of ferritin, C-reactive protein (CRP), D-dimer, lactate dehydrogenase (LDH), blood transaminases, body mass index, soluble interleukin-2 receptor (sIL2R), IL-1, IL-6, and TNF- $\alpha$ increase in patients with CoViD19 infection $[17,18]$. The amount of TNF- $\alpha$, IL-6, and IL-10 significantly increased in patients according to disease severity. In recovered patients, serum levels of IFN- $\gamma$, IL-10, IL-6, and TNF- $\alpha$ decreased compared with the illness period, while the population of total T cells, CD4+, and CD8+ T cell subsets recovered during improvement [10,19].

The case fatality rate (CFR) for CoViD-19 is unclear because the number of infected populations is not determined, but the WHO estimation is 0.3-1\%. Recent CoViD-19 case fatality rates are around $2 \%$, rising to $15 \%$ in patients aged 80 years. About $80 \%$ of patients have a mild or asymptomatic disease, $14 \%$ severe disease, and a $6 \%$ critical situation $[11,20]$. Furthermore, the mortality rate of patients with hematological diseases is approximately $46.7 \%$ [7]. In patients with hematological diseases, the rate of susceptibility and mortality to SARSCoV-2 is high, so it is important to prevent disease [7].

Similar to other viral infections, the body produces IgM and IgG antibodies against SARSCoV-2 and the SARS-specific IgM antibodies disappear at the end of week 12, and the $\operatorname{IgG}$ antibody can play a protective role [21].

A German pathologist first proposed the correlation between inflammation and cancer in the nineteenth century. It is now a critical hallmark of cancer [22]. It has recently been clear that inflammation plays roles in all stages of cancer development, including tumor initiation, promotion, progression, and metastasis [23,24]. Some cytokines and chemokines by inducing signaling pathways in the tumor microenvironment play an important role in cancer initiation and progression. The purpose of this review is the surviving probability of increasing the initiation and progression of different types of cancers following SARS-CoV-2 viral infection in convalescent patients. 


\section{SARS-COV-2 Detection}

Clinical evaluations are crucial in detecting people with fever and/or lower respiratory tract symptoms. They have also traveled from a high-risk area or have been exposed to close contact with confirmed or suspected CoViD-19 in the previous 14 days [6]. There are examinations such as high-throughput sequencing, CT scan, enzyme-linked immunosorbent assay (ELISA), and blood culture [21]. Moreover, SARS-CoV-2 has been detected in blood, urine, stool, upper and lower respiratory tract, and saliva using real-time polymerase chain reaction (RT-PCR) [6]. The virus exists in inclusion bodies in macrophages and pulmonary alveolar cells for at least 2 weeks, although the PCR test is negative [16].

\section{Cytokine Release Syndrome}

Cytokine release syndrome (CRS) is a systemic inflammatory reaction that occurs in response to microbial infections, which can be an important contributor to acute respiratory distress syndrome (ARDS), multiple organs dysfunction syndrome (MODS) [10], and hyperferritinemia [25]. In immune system-related diseases or immune-related therapy, such as CAR-T cell therapy, organ transplantation sepsis, and virus infection is seen CRS $[8,19]$. CRS is seen in malignancy, infection, systemic juvenile idiopathic arthritis, Epstein-Barr virus, hemophagocytic lymphohistiocytosis, influenza, and CoViD-19 [18]. CRS has vast mild to severe symptoms that involve fever, fatigue, headache, rash, arthralgia, myalgia, hypotension, vascular leakage, vasopressor-requiring circulatory shock, disseminated intravascular coagulation, and multi-organ system failure [26].

Cytokines are small soluble proteins, including interleukins, chemokines, interferons, lymphokines, and tumor necrosis factors produced by different cells, especially activated lymphocytes and macrophages $[27,28]$. They regulate the balance between cellular immunity and humoral immunity [28] and are produced in response to cellular stresses, including infection by pathogens, inflammation, or injury [29].

Cytokines and chemokines are components that promote angiogenesis, metastasis, subversion of adaptive immunity, and changing response to hormones and chemotherapeutic agents [30]. IL-1, IL-6, IL-17, interferon, and TNF families are the main pro-inflammatory cytokines [31]. The overproduction of early response pro-inflammatory cytokines (TNF- $\alpha$, IL6 , and IL-1 $\beta$ ) as cytokine storm leads to vascular hyperpermeability, multi-organ failure, and finally, death [32]. According to previous reports, the liver and kidney can be damaged in patients with CoViD-19 [33].

One of the main causes of death in CoViD-19 is acute respiratory distress syndrome (ARDS), a common immune-pathological event in SARS-CoV-2, SARS-CoV-1 MERS-CoV infections. Large amounts of pro-inflammatory cytokines release (IFN- $\alpha$, IFN- $\gamma$, IL-1 $\beta$, IL-6, IL-12, IL-18, IL-33, TNF- $\alpha$, TGF- $\beta$ ) and chemokines (CCL2, CCL3, CCL5, CXCL8, CXCL9, CXCL10, etc.) by immune effector cells in the disease cause a systemic inflammatory response $[20,21]$.

In most diseases with a cytokine storm, IL-6 is an excellent biomarker of severity and prognostic indicator [18,34]. IL-6 is produced by almost all stromal cells and B lymphocytes, T lymphocytes, macrophages, monocytes, Kupffer cells, dendritic cells, mast cells, and other non-lymphocytes, such as fibroblasts, endothelial cells, keratinocytes, glomerular mesangial cells, and tumor cells $[19,35,36]$. IL-6 sends out inflammatory signals from localized lesions to the whole body to trigger the host defense against pathological agents [34]. IL-6 plays a 
critical role in acute inflammation $[8,19]$ and induces a broad range of acute-phase proteins such as C-reactive protein (CRP), complement C3, serum amyloid A (SAA), fibrinogen, thrombopoietin, hepcidin, haptoglobin, $\alpha 1$-antichymotrypsin, and tissue factor [34,37]. Besides, IL-6 influences the balance of CD4+ T lymphocyte subsets and induces the production of B cell antibodies [28,37].

\section{Coagulation and COVID-19}

In CoViD-19, infection associated with thrombosis is several factors, including severe hypoxemia, inflammation, endothelial dysfunction, immobilization, respiratory failure, mechanical ventilation, and central venous catheter use [38]. The abnormal coagulation system is one of the inflammation hallmarks because of increased circulating inflammatory molecules [39]. CoViD-19 associated coagulopathy (CAC) leads to abnormal coagulation tests, and elevated D-dimer levels in patients are associated with increased mortality [5].

Microorganisms and their components by entering into the body induce tissue factors on monocytes and macrophages [5]. The tissue factor activates the coagulation cascade through the extrinsic pathway [40]. Endothelial cells and activated mononuclear cells produce proinflammatory cytokines in systemic inflammatory response syndromes [40]. Inflammatory cytokines and endothelial injury can increase tissue factor expression to induce thrombotic actions [38]. Pro-inflammatory cytokines and chemokines can affect all coagulation pathways [41]. IL-6 with up-regulation of tissue factor initiates coagulation [39,41].

IL-1 $\beta$, IL-6, and TNF- $\alpha$ increase in acute and chronic systemic inflammation and thrombin activation lead to coagulation system activation [39-41]. High levels of IL-6 in cytokine storms can activate vascular endothelial cells and the coagulation pathway [34]. IL-6 increases thrombin-antithrombin complexes and the prothrombin activation fragments in the plasma [42] and also IL-6 leads to vascular leakage and activation of disseminated intravascular coagulation (DIC) [26]. Fibrinogen is an acute-phase plasma protein that has a role in the coagulation pathway [39]. IL-6 induces fibrinogen synthesis by hepatocytes and increases the expression of the tissue factor $[5,42]$.

TNF- $\alpha$ induces early activation of coagulation factor $\mathrm{X}$, followed by a potent activation of prothrombin. Moreover, in cancer patients, TNF- $\alpha$ can release tissue-type plasminogen activator (tPA), urokinase-type plasminogen activator (UPA), and PAI-1 into circulation [42].

Activation of coagulation pathways during infection exacerbates the clinical symptoms of patients. Humiliating procoagulant-anticoagulant balance during infection leads to the development of micro thrombosis, DIC, multi-organ failure, and even pulmonary emboli [32]. Hypercoagulability is an important hallmark of systemic inflammation, and IL-1 $\beta$, IL-6, and IL-8 are cytokines that can cause platelet hyper-activation and spread [41]. Platelets express the IL1R1 receptor, which responds to IL-1 $\beta$ and has receptors for IL- $1 \beta$ and IL-6. IL-1 $\beta$ down-regulates thrombomodulin and leads to impairing protein $\mathrm{C}$. There is gp130 on resting platelets membranes, and IL-6 can affect platelet thrombogenicity [41].

\section{COVID-19 and Tumorigenesis}

Tumorigenesis is divided into three steps: tumor initiation, tumor promotion, and tumor progression [43]. The tumor microenvironment plays a crucial role in the initiation and progression of cancer. It plays an important role in the selection of malignant clones [44]. The tumor microenvironment regulates all cancer hallmarks, including inhibition of apoptosis, 
survival, proliferation, angiogenesis, invasiveness, metastasis, cancer cell metabolism regulation, and multiple signaling pathways that induce tumorigenesis [44]. About $80 \%$ of hepatocellular carcinoma cases are derived from chronic liver damage caused by either HBV or HCV infections in the world [22]. Chronic inflammation (viral and bacterial infections) stimulates the development and progression of malignant neoplasms. Only $10 \%$ of all cancers are linked to germline mutations, whereas the vast majority (90\%) are caused by acquired somatic mutations [22]. Colorectal cancer, liver cancer, pancreatic cancer, and lung cancer are initiated by inflammation, cytokines (TNF- $\alpha$, IL-1, and IL-6), and nuclear factor- $\kappa \mathrm{B}$ (NF- $\kappa \mathrm{B}$ ) $[43,45]$.

Inflammation is an important contributing factor in most solid and hematopoietic malignancies [43]. Inflammatory cytokines and growth factors enhance the proliferation of initiated tumor progenitor cells through NF- $\mathrm{kB}$ [43]. Bacterial and viral infections induce inflammation and increase cancer risk [23]. Inflammation helps almost all aspects of tumor development, and inflammatory signals often influence tumorigenesis by activating NF-kB and STAT3 [46]. Inflammation is a fast and primitive defense reaction to pathogens that limits tissue damage and stimulates repair mechanisms. It is initiated by local cells that detect pathogens or trauma and send chemical messengers to other cells [47]. On the other side, NF$\kappa \mathrm{B}$, directly and indirectly, controls inflammation, cancer cell proliferation and survival, epithelial to mesenchymal transition (EMT), invasive behavior, angiogenesis and metastasis, genetic and epigenetic alterations, cancer stem cell formation, cellular metabolism, and therapy resistance [43].

Upregulation of growth-signaling pathways in all eukaryotes has been shown to impact cellular processes leading to increased oxidative DNA damage and replication stress in a correlative manner. Fibroblast Growth Factor (FGF), Epidermal Growth Factor (EGF), Platelet-Derived Growth Factor (PDGF), TGF- $\alpha$, TGF- $\beta$, Erythropoietin, Insulin-Like Growth Factor 1 (IGF-1), Insulin-Like Growth Factor 2 (IGF-2), IL-1, IL-2, IL-6, IL-8, TNF- $\alpha$, TNF$\beta$, INF- $\gamma$, and Colony Stimulating Factors (CSFs) have growth factor activity [27]. The presence of several growth-promoting cytokines in a long period may induce replication stress and DNA breaks. Cytokines include IL-6, TNF- $\alpha$, and IL- $1 \beta$ are mostly considered as tumorpromoting. IL-6 and IL-8 play a significant role in tumor growth, angiogenesis, EMT, and invasiveness [27]. IL-6 drives cancer progression, metastasis, and cancer stem cell expansion by activating the signal transducers and activators of the transcription 3 (STAT3) signaling pathway [48]. Several transcription factors include NF-кB, STAT3, and AP-1. These are the major downstream effectors of cytokine signaling and are activated in most cancers [22]. IL-1, IL-6, and IL-8 activate STAT3/NF- $\kappa$ B pathways in tumor and stromal cells [49]. Inflammation and $\mathrm{NF}-\kappa \mathrm{B}$ promote the production of reactive oxygen species and reactive nitrogen species, induce DNA damage and oncogenic mutations, and affect tumor initiation [43].

IL-6/JAK/STAT3 signaling induces proliferation, survival, invasiveness, and tumor cells' metastasis in many human cancers. On the other hand, it strongly suppresses the antitumor immune response[36,49,50]. STAT3 promotes the IL6 gene and induces the expression of factors VEGF, matrix metalloproteinases (MMPs), IL-10, and TGF $\beta$ [50]. IL-6 by enhancing cell cycle progression and suppressing apoptosis has a tumor-promoting role [27].

The JAK/STAT pathway is a major mediator of cytokine signaling. The dysregulation of this pathway is a hallmark of myelofibrosis [29]. In general, the Janus kinases are critical for signaling many surface cytokine and growth factor receptors that intrinsic kinase activity and JAKs activate the STAT proteins. STAT heterodimers transmit the cytokine activation 
signals from the cytoplasm into the nucleus and induce the transcription of several downstream targets that can cause proliferation, differentiation, and the angiogenic cascade [29].

IL-6 has an important role in promoting metastasis to other tissues and organs [51]. Furthermore, it contributes to invasion and angiogenesis with overexpression of bFGF, MMP2, MMP-9, and VEGF [24,51]. According to previous studies, the level of IL-6 increases in different malignancies, including skin, breast, lung, esophageal, liver, pancreatic, gastric, colorectal, gynecological, prostate, kidney, bladder, and hematological cancers as well as melanoma [24,30]. IL-6 overexpression has been seen in almost all types of tumors in the serum and tumor tissues [44]. IL-6 affects cancer cells in two ways, including autocrine and paracrine mechanisms [51]. IL-6 regulates different cellular processes and has roles in the pathogenesis of various diseases such as myeloma, lymphoma, and acute leukemia [35]. IL-6 influences tumor cell survival, proliferation, angiogenesis, metastasis, cell adhesion, and inflammation [36]. Moreover, IL-6 directly or by leveling up of VEGF leads to vascular hyperpermeability [34].

Recent studies indicate that common cytokine signaling pathways may significantly contribute to acute myeloid leukemia (AML) cells' growth and survival. Cytokines like IL-1 $\beta$, TNF- $\alpha$, and IL- 6 as pro-inflammatory mediators promote AML aggressiveness, while antiinflammatory mediators such as TGF- $\beta$ and IL-10 appear to impede AML progression [52]. IL-6 plays in the pathogenesis of hematological malignancies such as chronic myeloid leukemia (CML), multiple myeloma, Hodgkin's lymphoma, and solid cancers like breast and prostate, and recently, pancreatic cancers [53].

Cancer patients with increased circulating IL-6 are generally associated with poor prognosis and shorter survival, but the lower levels are inverse [44,49]. In patients with chronic lymphocytic leukemia (CLL), high IL-6 levels in peripheral blood are correlated with a poor prognosis [54]. In some cases, the level of IL-6 increases in the plasma of CLL patients [54] A study on breast cancer showed that IL-6 plays a crucial role in converting non-cancer stem cells into cancer stem cells by regulating OCT-4 gene expression [55]. This cytokine activates JAK/STAT-3, Ras/mitogen-activated protein kinase (MAPK), and phosphoinositol-3 kinase (PI3K) -protein kinase B/Akt (PkB/Akt) [51]. IL-6 increases some survival proteins' expression, including Bcl-2, Bcl-XL, Mcl-1, and survivin [51].

Cytokines of the IL-6 family have an important role in generating normal stem/progenitor cells and cancer stem cells (CSCs) [24]. Also, IL-6 helps tumor growth with increasing telomerase activity that prevents cellular senescence [24]. IL-6 has a critical role in promoting cancer progression and severity [56]. The most common cancer-related cytokines IL-1, IL-4, and IL-6, are associated with tumor malignancy [57]. The pro-tumoral role of IL-6 in multiple myeloma has been demonstrated, and IL-6 deficient mice were resistant to murine plasmacytoma development [30].

IL-1, as a pleiotropic cytokine, promotes tumor proliferation, angiogenesis, and metastases [58]. IL-1 $\beta$ elevation is a frequent event in hematological malignancies. It has been described as a poor prognosis biomarker in AML patients [52]. IL-1 $\beta$ promotes angiogenesis and tumor invasiveness and also suppresses immune function [59].

TNF- $\alpha$ is a pleiotropic cytokine with roles in the initiation, promotion, and progression of various cancers by activating NF- $\mathrm{KB}$ in the cancer cells $[60,61]$ and induces IL-6 and IL-1 production [59]. For the first time, TNF- $\alpha$ was introduced as an anti-tumor factor in 1984. It is produced by macrophages, T lymphocytes, natural killer (NK) cells, and neutrophils as two bioactive forms, including the transmembrane form (tmTNF- $\alpha$ ) and secretory form (sTNF- $\alpha$ ) 
[60]. TNF- $\alpha$ has two receptors, including TNFRI, found on most cells, and TNFRII, which is primarily expressed on hemopoietic cells [61]. TNF receptor activation leads to the induction of genes involved in inflammation and cell survival [61].

An interesting example of cytokine-mediated carcinogenesis in human malignant mesothelioma that TNF- $\alpha$ has a role in this type of cancer. TNF- $\alpha$ influences the initiation and progression stages of all cancer types [27]. TNF- $\alpha$ activates NF- $\kappa B$, which induces the transcription of genes involved in cancer's major hallmarks, including cell survival, proliferation, and angiogenesis [27,29]. TNF- $\alpha$ launches flu-like symptoms with fever, general malaise, fatigue, lung injury, vascular leakage, cardiomyopathy, watery diarrhea, and acutephase proteins synthesis [26].

SARS-CoV-2 can cause CRS by inducing excessive and prolonged cytokine and chemokine responses in some patients [45]. SARS-CoV-2 infection in the respiratory system can activate both NF- $\kappa \mathrm{B}$ and STAT3 [2], so NF- $\kappa$ B proteins can accelerate cell proliferation, inhibit apoptosis, and promote cell migration invasion, and stimulate angiogenesis and metastasis and also regulate innate and adaptive immune responses [43].

\section{Conclusion}

Given that inflammation plays a crucial role during all stages of tumor development, future studies will undoubtedly uncover whether CoViD-19 infection can influence cancer initiation or even metastatic spread. This review collected some information about the cytokines, which increase in current pandemic viral infection, and the cytokines' correlation with cancer formation mechanisms. According to past reports, the current inflammation cytokines such as IL-6, IL-1, and TNF- $\alpha$ that level up in CoViD-19 infection can activate signaling pathways that change normal cells and promote cancer development. After evaluating current literature works, the data show that cytokine storms might influence different vulnerable cells so is required more research.

\section{Funding}

This research received no external funding.

\section{Acknowledgments}

This research has no acknowledgment.

\section{Conflicts of Interest}

The author declares that he has no conflict of interest.

\section{References}

1. Gosain, R.; Abdou, Y.; Singh, A.; Rana, N.; Puzanov, I.; Ernstoff, M.S. COVID-19 and Cancer: a Comprehensive Review. Curr. Oncol. Rep. 2020, 22, 53, https://doi.org/10.1007/s11912-020-00934-7.

2. Hirano, T.; Murakami, M. COVID-19: A new virus, but a familiar receptor and cytokine release syndrome. Immunity 2020, https://doi.org/10.1016/j.immuni.2020.04.003.

3. Yeoh, C.B.; Lee, K.J.; Rieth, E.F.; Mapes, R.; Tchoudovskaia, A.V.; Fischer, G.W.; Tollinche, L.E. COVID19 in the Cancer Patient. Anesth. Analg. 2020, 131, https://doi.org/10.1213/ANE.0000000000004884.

4. Abruzzese, E.; Luciano, L.; D’Agostino, F.; Trawinska, M.M.; Pane, F.; De Fabritiis, P. SARS-CoV-2 (COVID-19) and Chronic Myeloid Leukemia (CML): a case report and review of ABL kinase involvement in viral infection. Mediterr. J. Hematol. Infect. Dis. 2020, 12, https://doi.org/10.4084/MJHID.2020.031. 
5. Connors, J.M.; Levy, J.H. COVID-19 and its implications for thrombosis and anticoagulation. Blood 2020, 135, 2033-2040, https://doi.org/10.1182/blood.2020006000.

6. Ardura, M.I.; Hartley, D.M.; Dandoy, C.; Lehmann, L.; Jaglowski, S.; Auletta, J.J. Addressing the impact of the Coronavirus Disease (COVID-19) pandemic on hematopoietic cell transplantation: Learning networks as means for sharing best practices. Biol. Blood Marrow Transplant. 2020, https://doi.org/10.1016/j.bbmt.2020.04.018.

7. Wu, Y.; Chen, W.; Li, W.; Zhao, M.; Wei, Q.; Zhang, X.; Mei, H.; Wang, Y.; Hu, Y. Clinical Characteristics, Diagnosis, and Clinical Management of COVID-19 in Fifteen Patients with Haematological Disease-A Retrospective Analysis. Diagnosis, and Clinical Management of COVID-19 in Fifteen Patients with Haematological Disease-A Retrospective Analysis (4/7/2020) 2020, https://dx.doi.org/10.2139/ssrn.3572878.

8. Pearce, L.; Davidson, S.M.; Yellon, D.M. The cytokine storm of COVID-19: a spotlight on prevention and protection. Expert Opin. Ther. Targets 2020, 24, 723-730, https://doi.org/10.1080/14728222.2020.1783243.

9. Tian, S.; Xiong, Y.; Liu, H.; Niu, L.; Guo, J.; Liao, M.; Xiao, S.-Y. Pathological study of the 2019 novel coronavirus disease (COVID-19) through postmortem core biopsies. Mod. Pathol. 2020, 33, 1007-1014, https://doi.org/10.1038/s41379-020-0536-X.

10. Diao, B.; Wang, C.; Tan, Y.; Chen, X.; Liu, Y.; Ning, L.; Chen, L.; Li, M.; Liu, Y.; Wang, G.; Yuan, Z.; Feng, Z.; Zhang, Y.; Wu, Y.; Chen, Y. Reduction and Functional Exhaustion of T Cells in Patients With Coronavirus Disease 2019 (COVID-19). Front. Immunol. 2020, 11, 827, https://doi.org/10.3389/fimmu.2020.00827.

11. Weinkove, R.; McQuilten, Z.K.; Adler, J.; Agar, M.R.; Blyth, E.; Cheng, A.C.; Conyers, R.; Haeusler, G.M.; Hardie, C.; Jackson, C.; Lane, S.W.; Middlemiss, T.; Mollee, P.; Mulligan, S.P.; Ritchie, D.; Ruka, M.; Solomon, B.; Szer, J.; Thursky, K.A.; Wood, E.M.; Worth, L.J.; Yong, M.K.; Slavin, M.A.; Teh, B.W. Managing haematology and oncology patients during the COVID-19 pandemic: interim consensus guidance. Med. J. Aust. 2020, 212, 481-489, https://doi.org/10.5694/mja2.50607.

12. Garnica, M.; Maiolino, A. COVID and hematology: special considerations regarding patient safety, gold standard therapies and safety for health care professionals. Hematology, Transfusion and Cell Therapy 2020, 42, 111-112, https://doi.org/10.1016/j.htct.2020.04.001.

13. Hrusak, O.; Kalina, T.; Wolf, J.; Balduzzi, A.; Provenzi, M.; Rizzari, C.; Rives, S.; del Pozo Carlavilla, M.; Alonso, M.E.V.; Pinilla, N.D. Flash survey on SARS-CoV-2 infections in pediatric patients on anti-cancer treatment. Eur. J. Cancer 2020, https://doi.org/10.1016/j.ejca.2020.03.021.

14. Perini, G.F.; Fischer, T.; Gaiolla, R.D.; Rocha, T.B.; Bellesso, M.; Teixeira, L.L.C.; Delamain, M.T.; Scheliga, A.A.d.S.; Ribeiro, G.N.; Neto, J.V.; Baiocchi, O.C.C.G.; Abdo, A.N.R.; Arrais-Rodrigues, C.; Fogliatto, L.M.; Bigni, R.d.S.; Schaffel, R.; Biasoli, I.; Pereira, J.; Nabhan, S.K.; Souza, C.A.d.; Chiattone, C.S. How to manage lymphoid malignancies during novel 2019 coronavirus (CoVid-19) outbreak: a Brazilian task force recommendation. Hematology, Transfusion and Cell Therapy 2020, 42, 103-110, https://doi.org/10.1016/j.htct.2020.04.002.

15. Fan, B.E.; Chong, V.C.L.; Chan, S.S.W.; Lim, G.H.; Lim, K.G.E.; Tan, G.B.; Mucheli, S.S.; Kuperan, P.; Ong, K.H. Hematologic parameters in patients with COVID-19 infection. Am. J. Hematol. 2020, 95, E131E134, https://doi.org/10.1002/ajh.25774.

16. Soy, M.; Keser, G.; Atagündüz, P.; Tabak, F.; Atagündüz, I.; Kayhan, S. Cytokine storm in COVID-19: pathogenesis and overview of anti-inflammatory agents used in treatment. Clin. Rheumatol. 2020, 39, 20852094, https://doi.org/10.1007/s10067-020-05190-5.

17. England, J.T.; Abdulla, A.; Biggs, C.M.; Lee, A.Y.Y.; Hay, K.A.; Hoiland, R.L.; Wellington, C.L.; Sekhon, M.; Jamal, S.; Shojania, K.; Chen, L.Y.C. Weathering the COVID-19 storm: Lessons from hematologic cytokine syndromes. Blood Rev. 2020, 100707, https://doi.org/10.1016/j.blre.2020.100707.

18. Henderson, L.A.; Canna, S.W.; Schulert, G.S.; Volpi, S.; Lee, P.Y.; Kernan, K.F.; Caricchio, R.; Mahmud, S.; Hazen, M.M.; Halyabar, O.; Hoyt, K.J.; Han, J.; Grom, A.A.; Gattorno, M.; Ravelli, A.; De Benedetti, F.; Behrens, E.M.; Cron, R.Q.; Nigrovic, P.A. On the Alert for Cytokine Storm: Immunopathology in COVID19. Arthritis \& Rheumatology 2020, 72, 1059-1063, https://doi.org/10.1002/art.41285.

19. Zhang, C.; Wu, Z.; Li, J.-W.; Zhao, H.; Wang, G.-Q. Cytokine release syndrome in severe COVID-19: interleukin-6 receptor antagonist tocilizumab may be the key to reduce mortality. Int. J. Antimicrob. Agents 2020, 55, 105954, https://doi.org/10.1016/j.ijantimicag.2020.105954.

20. Metcalfe, S.M. Mesenchymal stem cells and management of COVID-19 pneumonia. Medicine in Drug Discovery 2020, 5, 100019, https://doi.org/10.1016/j.medidd.2020.100019. 
21. Li, X.; Geng, M.; Peng, Y.; Meng, L.; Lu, S. Molecular immune pathogenesis and diagnosis of COVID-19. Journal of Pharmaceutical Analysis 2020, 10, 102-108, https://doi.org/10.1016/j.jpha.2020.03.001.

22. Todoric, J.; Umemura, A.; Taniguchi, K.; Karin, M. Inflammation and cancer. Holland-Frei Cancer Medicine 2016, 1-8, https://doi.org/10.1002/9781119000822.hfcm027.

23. Grivennikov, S.I.; Greten, F.R.; Karin, M. Immunity, inflammation, and cancer. Cell 2010, 140, 883-899, https://doi.org/10.1016/j.cell.2010.01.025.

24. Taniguchi, K.; Karin, M. IL-6 and related cytokines as the critical lynchpins between inflammation and cancer. Semin. Immunol. 2014, 26, 54-74, https://doi.org/10.1016/j.smim.2014.01.001.

25. Behrens, E.M.; Koretzky, G.A. Review: Cytokine Storm Syndrome: Looking Toward the Precision Medicine Era. Arthritis \& Rheumatology 2017, 69, 1135-1143, https://doi.org/10.1002/art.40071.

26. Shimabukuro-Vornhagen, A.; Gödel, P.; Subklewe, M.; Stemmler, H.J.; Schlößer, H.A.; Schlaak, M.; Kochanek, M.; Böll, B.; von Bergwelt-Baildon, M.S. Cytokine release syndrome. Journal for ImmunoTherapy of Cancer 2018, 6, 56, https://doi.org/10.1186/s40425-018-0343-9.

27. Aivaliotis, I.L.; Pateras, I.S.; Papaioannou, M.; Glytsou, C.; Kontzoglou, K.; Johnson, E.O.; Zoumpourlis, V. How Do Cytokines Trigger Genomic Instability? J. Biomed. Biotechnol. 2012, 2012, 536761, https://doi.org/10.1155/2012/536761.

28. Zhu, H.; Wang, Z.; Yu, J.; Yang, X.; He, F.; Liu, Z.; Che, F.; Chen, X.; Ren, H.; Hong, M.; Wang, J. Role and mechanisms of cytokines in the secondary brain injury after intracerebral hemorrhage. Prog. Neurobiol. 2019, 178, 101610, https://doi.org/10.1016/j.pneurobio.2019.03.003.

29. Hasselbalch, H.C. The role of cytokines in the initiation and progression of myelofibrosis. Cytokine Growth Factor Rev. 2013, 24, 133-145, https://doi.org/10.1016/j.cytogfr.2013.01.004.

30. Germano, G.; Allavena, P.; Mantovani, A. Cytokines as a key component of cancer-related inflammation. Cytokine 2008, 43, 374-379, https://doi.org/10.1016/j.cyto.2008.07.014.

31. Mosevoll, K.A.; Johansen, S.; Wendelbo, Ø.; Nepstad, I.; Bruserud, Ø.; Reikvam, H. Cytokines, Adhesion Molecules, and Matrix Metalloproteases as Predisposing, Diagnostic, and Prognostic Factors in Venous Thrombosis. Frontiers in Medicine 2018, 5, 147, https://doi.org/10.3389/fmed.2018.00147.

32. Jose, R.J.; Manuel, A. COVID-19 cytokine storm: the interplay between inflammation and coagulation. The Lancet Respiratory Medicine 2020, https://doi.org/10.1016/s2213-2600(20)30216-2.

33. Rismanbaf, A.; Zarei, S. Liver and Kidney Injuries in COVID-19 and Their Effects on Drug Therapy; a Letter to Editor. Archives of Academic Emergency Medicine 2020, 8, e17, https://doi.org/10.22037/aaem.v8i1.590.

34. Tanaka, T.; Narazaki, M.; Kishimoto, T. Immunotherapeutic implications of IL-6 blockade for cytokine storm. Immunotherapy 2016, 8, 959-970, https://doi.org/10.2217/imt-2016-0020.

35. Allahbakhshian Farsani, M.; Kamel, M.; Mehrpouri, M.; Heris, R.S.; Hamidpour, M.; Salari, S.; Mohamadi, M.H. The Expression of Interferon Gamma (IFN- $\gamma$ ) and Interleukin 6 (IL6) in Patients with Acute Lymphoblastic Leukemia (ALL). Pathology \& Oncology Research 2020, 26, 461-466, https://doi.org/10.1007/s12253-018-0536-z.

36. Chonov, D.C.; Ignatova, M.M.K.; Ananiev, J.R.; Gulubova, M.V. IL-6 Activities in the Tumour Microenvironment. Part 1. Open Access Macedonian Journal of Medical Sciences 2019, 7, 2391-2398, https://doi.org/10.3889/oamjms.2019.589.

37. Tanaka, T.; Narazaki, M.; Kishimoto, T. Interleukin (IL-6) immunotherapy. Cold Spring Harb. Perspect. Biol. 2018, 10, a028456, https://doi:10.1101/cshperspect.a028456.

38. Marchandot, B.; Sattler, L.; Jesel, L.; Matsushita, K.; Schini-Kerth, V.; Grunebaum, L.; Morel, O. COVID19 Related Coagulopathy: A Distinct Entity? Journal of Clinical Medicine 2020, 9, 1651, https://doi.org/10.3390/jcm9061651.

39. Bester, J.; Matshailwe, C.; Pretorius, E. Simultaneous presence of hypercoagulation and increased clot lysis time due to IL-1ß, IL-6 and IL-8. Cytokine 2018, 110, 237-242, https://doi.org/10.1016/j.cyto.2018.01.007.

40. Okamoto, K.; Tamura, T.; Sawatsubashi, Y. Sepsis and disseminated intravascular coagulation. Journal of intensive care 2016, 4, 1-8. https://doi.org/10.1186/s40560-016-0149-0.

41. Bester, J.; Pretorius, E. Effects of IL-1 $\beta$, IL-6 and IL-8 on erythrocytes, platelets and clot viscoelasticity. Sci. Rep. 2016, 6, 32188, https://doi.org/10.1038/srep32188.

42. Bazan-Socha, S.; Mastalerz, L.; Cybulska, A.; Zareba, L.; Kremers, R.; Zabczyk, M.; Pulka, G.; Iwaniec, T.; Hemker, C.; Undas, A. Prothrombotic State in Asthma Is Related to Increased Levels of Inflammatory Cytokines, IL-6 and TNF $\alpha$, in Peripheral Blood. Inflammation 2017, 40, 1225-1235, https://doi.org/10.1007/s10753-017-0565-x. 
43. Taniguchi, K.; Karin, M. NF-кB, inflammation, immunity and cancer: coming of age. Nature Reviews Immunology 2018, 18, 309-324, https://doi.org/10.1038/nri.2017.142.

44. Kumari, N.; Dwarakanath, B.S.; Das, A.; Bhatt, A.N. Role of interleukin-6 in cancer progression and therapeutic resistance. Tumor Biol. 2016, 37, 11553-11572, https://doi.org/10.1007/s13277-016-5098-7.

45. Ye, Q.; Wang, B.; Mao, J. The pathogenesis and treatment of theCytokine Storm'in COVID-19. J. Infect. 2020, 80, 607-613, https://doi.org/10.1016/j.jinf.2020.03.037.

46. Li, N.; Grivennikov, S.I.; Karin, M. The unholy trinity: inflammation, cytokines, and STAT3 shape the cancer microenvironment. Cancer Cell 2011, 19, 429-431, https://doi.org/10.1016/j.ccr.2011.03.018.

47. Munn, L.L. Cancer and inflammation. WIREs Systems Biology and Medicine 2017, 9, e1370, https://doi.org/10.1002/wsbm.1370.

48. Wang, C.-Q.; Sun, H.-T.; Gao, X.-M.; Ren, N.; Sheng, Y.-Y.; Wang, Z.; Zheng, Y.; Wei, J.-W.; Zhang, K.L.; Yu, X.-X.; Zhu, Y.; Luo, Q.; Yang, L.-Y.; Dong, Q.-Z.; Qin, L.-X. Interleukin-6 enhances cancer stemness and promotes metastasis of hepatocellular carcinoma via up-regulating osteopontin expression. Am. J. Cancer Res. 2016, 6, 1873-1889.

49. Korkaya, H.; Liu, S.; Wicha, M.S. Regulation of Cancer Stem Cells by Cytokine Networks: Attacking Cancer's Inflammatory Roots. Clin. Cancer. Res. 2011, 17, 6125, https://doi.org/10.1158/1078-0432.CCR10-2743.

50. Johnson, D.E.; O'Keefe, R.A.; Grandis, J.R. Targeting the IL-6/JAK/STAT3 signalling axis in cancer. Nature Reviews Clinical Oncology 2018, 15, 234-248, https://doi.org/10.1038/nrclinonc.2018.8.

51. Ara, T.; DeClerck, Y.A. Interleukin-6 in bone metastasis and cancer progression. Eur. J. Cancer 2010, 46, 1223-1231, https://doi.org/10.1016/j.ejca.2010.02.026.

52. Binder, S.; Luciano, M.; Horejs-Hoeck, J. The cytokine network in acute myeloid leukemia (AML): A focus on pro- and anti-inflammatory mediators. Cytokine Growth Factor Rev. 2018, 43, 8-15, https://doi.org/10.1016/j.cytogfr.2018.08.004.

53. Reynaud, D.; Pietras, E.; Barry-Holson, K.; Mir, A.; Binnewies, M.; Jeanne, M.; Sala-Torra, O.; Radich, J.P.; Passegué, E. IL-6 controls leukemic multipotent progenitor cell fate and contributes to chronic myelogenous leukemia development. Cancer Cell 2011, 20, 661-673, https://doi.org/10.1016/j.ccr.2011.10.012.

54. Zhu, F.; McCaw, L.; Spaner, D.E.; Gorczynski, R.M. Targeting the IL-17/IL-6 axis can alter growth of Chronic Lymphocytic Leukemia in vivo/in vitro. Leukemia Res. 2018, 66, 28-38, https://doi.org/10.1016/j.leukres.2018.01.006.

55. Kim, S.-Y.; Kang, J.W.; Song, X.; Kim, B.K.; Yoo, Y.D.; Kwon, Y.T.; Lee, Y.J. Role of the IL-6-JAK1STAT3-Oct-4 pathway in the conversion of non-stem cancer cells into cancer stem-like cells. Cell. Signal. 2013, 25, 961-969, https://doi.org/10.1016/j.cellsig.2013.01.007.

56. Tian, G.; Mi, J.; Wei, X.; Zhao, D.; Qiao, L.; Yang, C.; Li, X.; Zhang, S.; Li, X.; Wang, B. Circulating interleukin-6 and cancer: A meta-analysis using Mendelian randomization. Sci. Rep. 2015, 5, 11394, https://doi.org/10.1038/srep11394.

57. Setrerrahmane, S.; Xu, H. Tumor-related interleukins: old validated targets for new anti-cancer drug development. Mol. Cancer 2017, 16, 153, https://doi.org/10.1186/s12943-017-0721-9.

58. Lewis, A.M.; Varghese, S.; Xu, H.; Alexander, H.R. Interleukin-1 and cancer progression: the emerging role of interleukin-1 receptor antagonist as a novel therapeutic agent in cancer treatment. J. Transl. Med. 2006, 4, 48, https://doi.org/10.1186/1479-5876-4-48.

59. Sanchez-Correa, B.; Bergua, J.M.; Campos, C.; Gayoso, I.; Arcos, M.J.; Bañas, H.; Morgado, S.; Casado, J.G.; Solana, R.; Tarazona, R. Cytokine profiles in acute myeloid leukemia patients at diagnosis: Survival is inversely correlated with IL-6 and directly correlated with IL-10 levels. Cytokine 2013, 61, 885-891, https://doi.org/10.1016/j.cyto.2012.12.023.

60. Zhou, X.; Li, Z.; Zhou, J. Tumor necrosis factor $\alpha$ in the onset and progression of leukemia. Exp. Hematol. 2017, 45, 17-26, https://doi.org/10.1016/j.exphem.2016.10.005.

61. Balkwill, F. TNF- $\alpha$ in promotion and progression of cancer. Cancer Metastasis Rev. 2006, 25, 409, https://doi.org/10.1007/s10555-006-9005-3. 